\title{
A Novel Load-Balancing Method and Device by Intelligent Grouping Compound Switches-Based Capacitor Banks Shunt Compensation
}

\author{
Qiuye Sun, Jianguo Zhou, Xinrui Liu, and Jun Yang \\ Department of Electrical Engineering, Northeastern University, Box 134, Wenhua Road 3-11, \\ Shenyang 110819, China
}

Correspondence should be addressed to Jianguo Zhou; sunqiuye@ise.neu.edu.cn

Received 25 November 2012; Accepted 9 April 2013

Academic Editor: Yuji Liu

Copyright (C) 2013 Qiuye Sun et al. This is an open access article distributed under the Creative Commons Attribution License, which permits unrestricted use, distribution, and reproduction in any medium, provided the original work is properly cited.

\begin{abstract}
A novel compensator topology is proposed for three-phase unbalanced loads in the distribution networks. The negative and zero sequence compensation networks are proposed using delta-connected and star-connected capacitor banks. The compensation networks are paralleled with the unbalanced load to achieve a perfect balancing of active power and a complete compensation of reactive power of the unbalanced load. Intelligent grouping compound switches are implemented to control the capacitors, where, therefore, each capacitor can be switched between phases or phase and ground. Wireless sensors are also applied to acquire the load quantities. The compensation method proposed is based on symmetrical component theory. In addition, the load compensation based on instantaneous symmetrical component theory with positive sequence online extraction is proposed under unbalanced and distorted source voltages. The proposed load-balancing method and device are applied to Liaoning, Neimenggu, and Jilin provinces. The application results are provided to validate the performance of the proposed compensator topology and compensation method.
\end{abstract}

\section{Introduction}

At present, the low-voltage three-phase four-wire distribution systems are facing the poor power quality problems such as high reactive power burden, unbalanced load, excessive neutral current, and voltage distortion. The power quality problems are mainly due to the proliferation of different types of nonlinear loads connected to the utility through residential, commercial, and industrial customers, unplanned expansion of the distribution system, and so forth [1-4]. There are some typical single-phase loads such as computer loads, lighting ballasts, small-rating adjustable speeds drives (ASDs) in air conditioners, fans, refrigerators, and other domestic and commercial appliances. These loads can result in harmonic pollution, three-phase loads unbalance, and overload of neutral conductor which may cause many adverse effects such as overloading power feeders, overloading distribution transformers, voltage distortion, common mode noise, and higher costs.
To solve the problems of reactive power compensation, load balancing, and harmonic elimination, some methods have been developed.

A combined system of a static var compensator (SVC) and a series active filter $[5,6]$ has been proposed to compensate the unbalanced load and reactive power. The SVC which consists of delta-connected thyristor-controlled reactors and star-connected thyristor-controlled reactors and passive filters acts as a classic reactive power compensator for load balancing and power factor correction. With the rapid development and wide application of power electronics technology, some advanced equipmentsare being developed. Active power filter (APF), combinations of APF and thyristor binary compensator (TBC), capacitor-clamped APF and DSTATCOM [7-12], and voltage source inverter (VSI) [1315] have been proposed to compensate reactive power and unbalanced load and eliminate harmonics. A loop power controller for load balancing of distribution feeders considering photovoltaic generation has been proposed [16]. The theory 


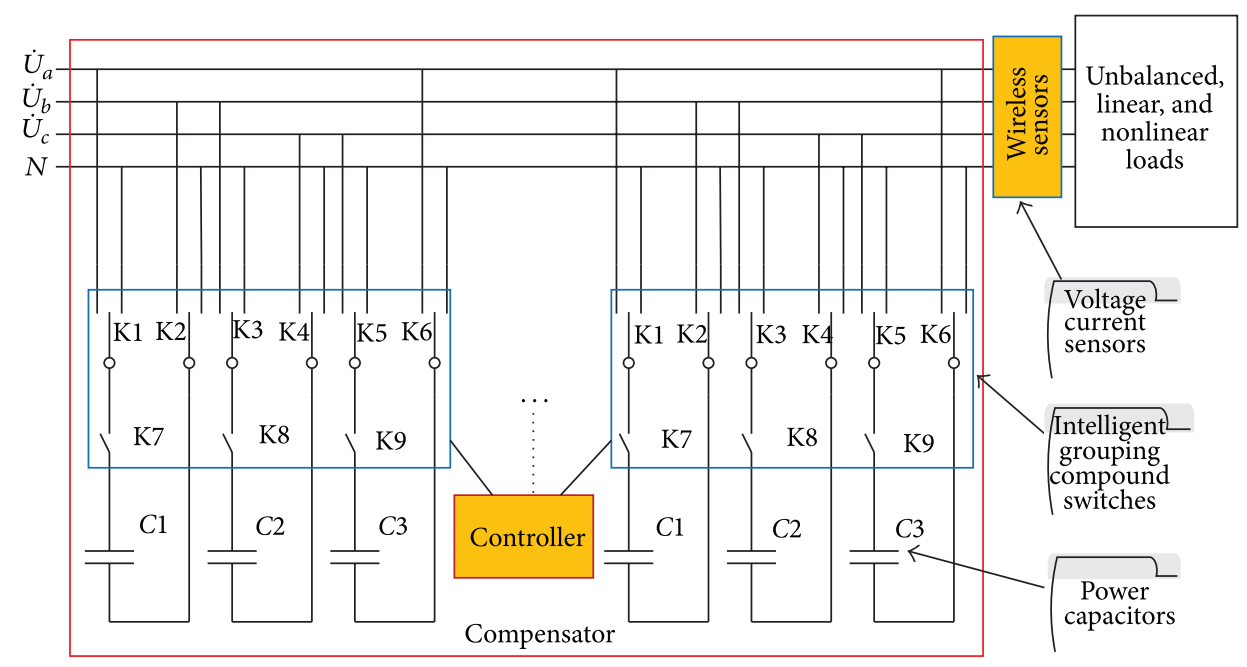

FIgURE 1: The basic power circuit topology of the proposed compensator.

of instantaneous symmetrical components $[7,13]$ is applied to explore various control strategies of load compensation. Adaptive control strategies $[10,15,17,18]$ and decoupled $d-q$ axes control scheme [11] are proposed to achieve load balancing and reactive compensation. For the combination of $\mathrm{APF}$ and $\mathrm{TBC}[8]$, the TBC compensates reactive power and balances the load, but it needs enormous capacitors and the utilization is not high, and three-phase four-wire system is not considered. The voltage-source inverter [9] for APF is based on a three-level capacitor-clamped topology to reduce the voltage stress of power semiconductors, so the compensator structure and the control are complex.

Dynamic capacitor (D-CAP) and antiresonance hybrid delta-connected capacitor bank $[19,20]$ are proposed to achieve reactive power compensation and harmonic elimination, both of which lots of power switches are adopted. So the cost is increased and the control is not easy. In addition, unbalanced source/load and three-phased fourwire system are not considered. A numerical approach for load balancing by unbalanced capacitive shunt compensation has been proposed in a three-phase three-wire network [21]. The shunt compensator is delta connection and contains only capacitive susceptances and/or inductive susceptances. But other problems need to be taken into account, such as unbalanced source currents and/or excessive current flowing through the neutral conductor. And these problems are mainly caused by unbalanced loads connected to three-phase four-wire systems.

To overcome the aforementioned problems, a new topology of compensator based on intelligent grouping compound switch combined with power capacitors is presented in this paper. The compensator includes delta-connected capacitor banks and star-connected capacitor banks. The deltaconnected capacitor banks determine the redistribution of active power between the phases and compensate a part of the reactive power of load. The star-connected capacitor banks are used to compensate the other part of the reactive power of load. This method can make the ensemble loadcompensator perfectly balanced and have the desired power factor. Intelligent grouping compound switches are used to control the capacitors so that each capacitor can be connected to two phases or one phase and the neutral line, yielding smaller volume, lower costs, utilization of the capacitor, and more flexible control. Additionally, in order to avoid the use of the communication wire line and to improve the system reliability, wireless sensors are also applied to acquire the realtime unbalanced load quantities in this paper.

\section{The Proposed Compensator Configuration with Wireless Sensors}

Figure 1 shows the basic power circuit topology of the proposed compensator applied to low-voltage three-phase fourwire distribution networks for load balancing and reactive power compensation.

The unbalanced, linear, and nonlinear loads are connected at the PCC. The compensator comprises capacitors and intelligent grouping compound switches. Each capacitor is connected to the intelligent grouping compound switches. And the capacity of the capacitors is unequal. In order to monitor the system and apply quantities of the loads, wireless voltage/current sensors are installed on the load side. From Figure 1, we can see that each capacitor can be switched between phase and phase or between phase and ground by using intelligent grouping compound switches controlled by the controller. Compared with the conventional compensation methods, this method will conduce to small volume, low costs, flexible control, capacitor utilization, and high accuracy.

\section{The Compensation Principle}

3.1. The Direct Application of Symmetrical Component Theory. The compensation principle graph of the compensator structure is shown in Figure 2. $\dot{U}_{a}, \dot{U}_{b}$, and $\dot{U}_{c}$ are the three-phase source voltages; $\dot{I}_{s a}, \dot{I}_{s b}$, and $\dot{I}_{s c}$ are the source line currents; $\dot{I}_{L a}, \dot{I}_{L b}$, and $\dot{I}_{L c}$ are the load line currents; $\dot{I}_{L N}$ is neutral 


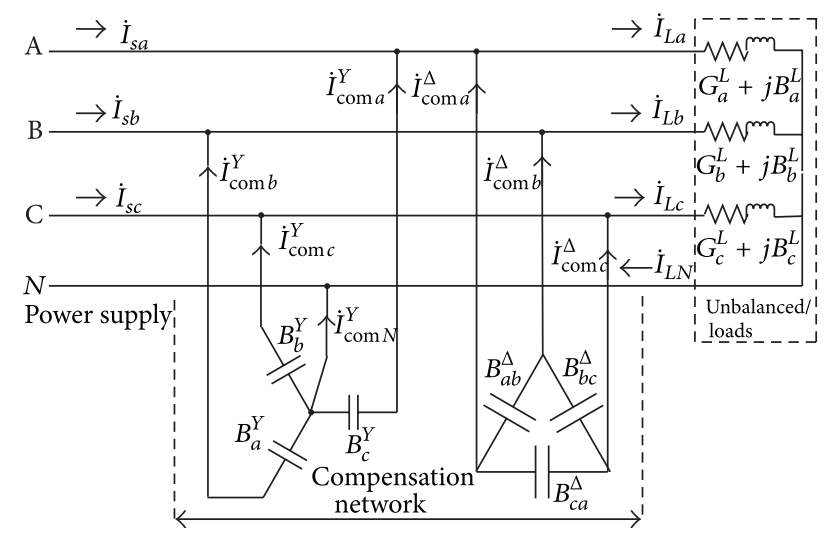

FIGURE 2: Compensation principle graph of the compensator structure.

current; $\dot{I}_{\text {coma }}^{Y}, \dot{I}_{\text {comb }}^{Y}$, and $\dot{I}_{\text {comc }}^{Y}$ are the currents of the starconnected compensation capacitors; $\dot{I}_{\text {com } N}^{Y}$ is the neutral line current; $\dot{I}_{\text {coma } a}^{\Delta} \dot{I}_{\text {comb } b}^{\Delta}$, and $\dot{I}_{\text {comc }}^{\Delta}$ are the currents of the deltaconnected capacitors. $G_{a}^{L}+j B_{a}^{L}, G_{b}^{L}+j B_{b}^{L}$, and $G_{c}^{L}+j B_{c}^{L}$ are the admittance of load and $j B_{a}^{Y}, j B_{b}^{Y}, j B_{c}^{Y}$ and $j B_{a b}^{\Delta}, j B_{b c}^{\Delta}, j B_{c a}^{\Delta}$ are the admittance of the star-connected and delta-connected compensation capacitors, respectively.

The supply voltage is considered symmetrical and balanced and described as $\dot{U}_{a}=\dot{U}, \dot{U}_{b}=a^{2} \dot{U}$ and $\dot{U}_{c}=a \dot{U}$, where $\dot{U}=U \angle 0^{\circ}$ and $a=e^{j 120^{\circ}}$. According to Figure 2, the load current can be expressed as

$$
\left[\begin{array}{c}
\dot{I}_{L a} \\
\dot{I}_{L b} \\
\dot{I}_{L c}
\end{array}\right]=U\left[\begin{array}{c}
G_{a}^{L}+j B_{a}^{L} \\
a^{2}\left(G_{b}^{L}+j B_{b}^{L}\right) \\
a\left(G_{c}^{L}+j B_{c}^{L}\right)
\end{array}\right] .
$$

Using a similar way, the compensation current can also be presented as

$$
\begin{aligned}
{\left[\begin{array}{l}
\dot{I}_{\text {com } a}^{\Delta} \\
\dot{I}_{\text {com } b}^{\Delta} \\
\dot{I}_{\text {comc }}^{\Delta}
\end{array}\right]=j U\left[\begin{array}{c}
\left(a^{2}-1\right) B_{a b}^{\Delta}+(a-1) B_{c a}^{\Delta} \\
\left(1-a^{2}\right) B_{a b}^{\Delta}+\left(a-a^{2}\right) B_{b c}^{\Delta} \\
\left(a^{2}-a\right) B_{b c}^{\Delta}+(1-a) B_{c a}^{\Delta}
\end{array}\right], } \\
{\left[\begin{array}{c}
\dot{I}_{\text {com } a}^{Y} \\
\dot{I}_{\text {comb }}^{Y} \\
\dot{I}_{\text {comc }}^{Y}
\end{array}\right]=j U\left[\begin{array}{c}
B_{a}^{Y} \\
a^{2} B_{b}^{Y} \\
a B_{c}^{Y}
\end{array}\right] . }
\end{aligned}
$$

Applying the symmetrical component theory [22], the load current can be resolved into three components: positive sequence, negative sequence, and zero sequence. So the symmetrical components of the load current are obtained by

$$
\begin{aligned}
& {\left[\begin{array}{l}
\dot{I}_{L 0} \\
\dot{I}_{L+} \\
\dot{I}_{L-}
\end{array}\right]} \\
& \quad=\frac{1}{3}\left[\begin{array}{ccc}
1 & 1 & 1 \\
1 & a & a^{2} \\
1 & a^{2} & a
\end{array}\right]\left[\begin{array}{c}
\dot{I}_{L a} \\
\dot{I}_{L b} \\
\dot{I}_{L c}
\end{array}\right] \\
& =\frac{U}{3}\left[\begin{array}{c}
\left(G_{a}^{L}+a^{2} G_{b}^{L}+a G_{c}^{L}\right)+j\left(B_{a}^{L}+a^{2} B_{b}^{L}+a B_{c}^{L}\right) \\
\left(G_{a}^{L}+G_{b}^{L}+G_{c}^{L}\right)+j\left(B_{a}^{L}+B_{b}^{L}+B_{c}^{L}\right) \\
\left(G_{a}^{L}+a G_{b}^{L}+a^{2} G_{c}^{L}\right)+j\left(B_{a}^{L}+a B_{b}^{L}+a^{2} B_{c}^{L}\right)
\end{array}\right],
\end{aligned}
$$

where $\dot{I}_{L 0}, \dot{I}_{L+}$, and $\dot{I}_{L-}$ are zero sequence, positive sequence, and negative sequence of the load current, respectively.

The symmetrical components of the compensation current can also be given, using a similar transform, by

$$
\begin{gathered}
{\left[\begin{array}{l}
\dot{I}_{\mathrm{com} 0}^{\Delta} \\
\dot{I}_{\mathrm{com}+}^{\Delta} \\
\dot{I}_{\mathrm{com}-}^{\Delta}
\end{array}\right]=j U\left[\begin{array}{c}
0 \\
B_{a b}^{\Delta}+B_{b c}^{\Delta}+B_{c a}^{\Delta} \\
-\left(a^{2} B_{a b}^{\Delta}+B_{b c}^{\Delta}+a B_{c a}^{\Delta}\right)
\end{array}\right],} \\
{\left[\begin{array}{c}
\dot{I}_{\mathrm{com} 0}^{Y} \\
\dot{I}_{\mathrm{com}+}^{Y} \\
\dot{I}_{\mathrm{com}-}^{Y}
\end{array}\right]=j \frac{U}{3}\left[\begin{array}{c}
B_{a}^{Y}+a^{2} B_{b}^{Y}+a B_{c}^{Y} \\
B_{a}^{Y}+B_{b}^{Y}+B_{c}^{Y} \\
B_{a}^{Y}+a B_{b}^{Y}+a^{2} B_{c}^{Y}
\end{array}\right],}
\end{gathered}
$$

where $\dot{I}_{\text {com } 0}^{\Delta}, \dot{I}_{\text {com+ }+}^{\Delta}, \dot{I}_{\text {com- }}^{\Delta}$ and $\dot{I}_{\text {com0 } 0}^{Y}, \dot{I}_{\text {com+ }+}^{Y}, \dot{I}_{\text {com- }}^{Y}$ are zero sequence, positive sequence, and negative sequence of the compensation currents of delta-connected and starconnected compensation capacitors, respectively.

In order to balance the load and compensate the reactive power, the three-phase current after compensation should be satisfied:

$$
\begin{aligned}
& \operatorname{Re}\left(\dot{I}_{L 0}+\dot{I}_{\text {com } 0}^{Y}+\dot{I}_{\text {com } 0}^{\Delta}\right)=0, \\
& \operatorname{Im}\left(\dot{I}_{L 0}+\dot{I}_{\text {com } 0}^{Y}+\dot{I}_{\text {com } 0}^{\Delta}\right)=0, \\
& \operatorname{Re}\left(\dot{I}_{L-}+\dot{I}_{\text {com- }}^{Y}+\dot{I}_{\text {com- }}^{\Delta}\right)=0, \\
& \operatorname{Im}\left(\dot{I}_{L-}+\dot{I}_{\text {com- }}^{Y}+\dot{I}_{\text {com- }}^{\Delta}\right)=0, \\
& \operatorname{Im}\left(\dot{I}_{L+}+\dot{I}_{\text {com }+}^{Y}+\dot{I}_{\text {com- }}^{\Delta}\right)=0 .
\end{aligned}
$$

Combining (3) and (4) and submitting in (5), the following can be obtained:

$$
\begin{aligned}
& \frac{\sqrt{3}}{2}\left(B_{b}^{Y}-B_{c}^{Y}\right)=-G_{a}^{L}+\frac{1}{2} G_{b}^{L}+\frac{1}{2} G_{c}^{L}-\frac{\sqrt{3}}{2} B_{b}^{L}+\frac{\sqrt{3}}{2} B_{c}^{L}, \\
& B_{a}^{Y}-\frac{1}{2}\left(B_{b}^{Y}+B_{c}^{Y}\right)=\frac{\sqrt{3}}{2} G_{b}^{L}-\frac{\sqrt{3}}{2} G_{c}^{L}-B_{a}^{L}+\frac{1}{2} B_{b}^{L}+\frac{1}{2} B_{c}^{L},
\end{aligned}
$$




$$
\begin{gathered}
\left(B_{a}^{Y}+B_{b}^{Y}+B_{c}^{Y}\right)+3\left(B_{a b}^{\Delta}+B_{b c}^{\Delta}+B_{c a}^{\Delta}\right)=-\left(B_{a}^{L}+B_{b}^{L}+B_{c}^{L}\right), \\
\frac{1}{\sqrt{3}}\left(B_{b}^{Y}-B_{c}^{Y}\right)+\sqrt{3}\left(B_{a b}^{\Delta}-B_{c a}^{\Delta}\right) \\
=\frac{2}{3} G_{a}^{L}-\frac{1}{3} G_{b}^{L}-\frac{1}{3} G_{c}^{L}-\frac{1}{\sqrt{3}} B_{b}^{L}+\frac{1}{\sqrt{3}} B_{c}^{L} \\
\frac{1}{3}\left[2 B_{a}^{Y}-\left(B_{b}^{Y}+B_{c}^{Y}\right)\right]+\left[\left(B_{a b}^{\Delta}+B_{c a}^{\Delta}\right)-2 B_{b c}^{\Delta}\right] \\
=-\frac{1}{\sqrt{3}} G_{b}^{L}+\frac{1}{\sqrt{3}} G_{c}^{L}-\frac{2}{3} B_{a}^{L}+\frac{1}{3} B_{b}^{L}+\frac{1}{3} B_{c}^{L} .
\end{gathered}
$$

Obviously, there is no unique solution for (6). The optimization is essential. Taking the technical difficulty of design and the total costs into account, the minimum of the sum of the squared compensation currents (defined as (7)) is used as a constraint:

$$
\begin{aligned}
H= & \left(B_{a}^{Y} U\right)^{2}+\left(B_{b}^{Y} U\right)^{2}+\left(B_{c}^{Y} U\right)^{2} \\
& +\left(\sqrt{3} B_{a b}^{\Delta} U\right)^{2}+\left(\sqrt{3} B_{b c}^{\Delta} U\right)^{2}+\left(\sqrt{3} B_{c a}^{\Delta} U\right)^{2},
\end{aligned}
$$

where $B_{b}^{Y}, B_{c}^{Y}, B_{a b}^{\Delta}, B_{b c}^{\Delta}$, and $B_{c a}^{\Delta}$ can be expressed in the form of $B_{a}^{Y}$. So $H_{\min }$ is obtained by solving

$$
\frac{d H}{d B_{a}^{Y}}=0 .
$$

Finally, combining (6), (7), and (8), the parameters of the compensator can be obtained as

$$
\begin{aligned}
& \left.\left[\begin{array}{c}
B_{a}^{Y} \\
B_{b}^{Y} \\
B_{c}^{Y} \\
B_{b c}^{\Delta} \\
B_{c a}^{\Delta} \\
B_{a b}^{\Delta}
\end{array}\right] \begin{array}{cccccc}
0 & \frac{1}{\sqrt{3}} & -\frac{1}{\sqrt{3}} & -\frac{3}{4} & \frac{1}{4} & \frac{1}{4} \\
-\frac{1}{\sqrt{3}} & 0 & \frac{1}{\sqrt{3}} & \frac{1}{4} & -\frac{3}{4} & \frac{1}{4} \\
\frac{1}{\sqrt{3}} & -\frac{1}{\sqrt{3}} & 0 & \frac{1}{4} & \frac{1}{4} & -\frac{3}{4} \\
0 & \frac{2}{3 \sqrt{3}} & -\frac{2}{3 \sqrt{3}} & -\frac{1}{12} & -\frac{1}{12} & -\frac{1}{12} \\
\frac{2}{3 \sqrt{3}} & 0 & \frac{2}{3 \sqrt{3}} & -\frac{1}{12} & -\frac{1}{12} & -\frac{1}{12} \\
\frac{2}{3 \sqrt{3}} & -\frac{2}{3 \sqrt{3}} & 0 & -\frac{1}{12} & -\frac{1}{12} & -\frac{1}{12}
\end{array}\right]\left[\begin{array}{l}
G_{a}^{L} \\
G_{b}^{L} \\
G_{c}^{L} \\
B_{a}^{L} \\
B_{b}^{L} \\
B_{c}^{L}
\end{array}\right] .
\end{aligned}
$$

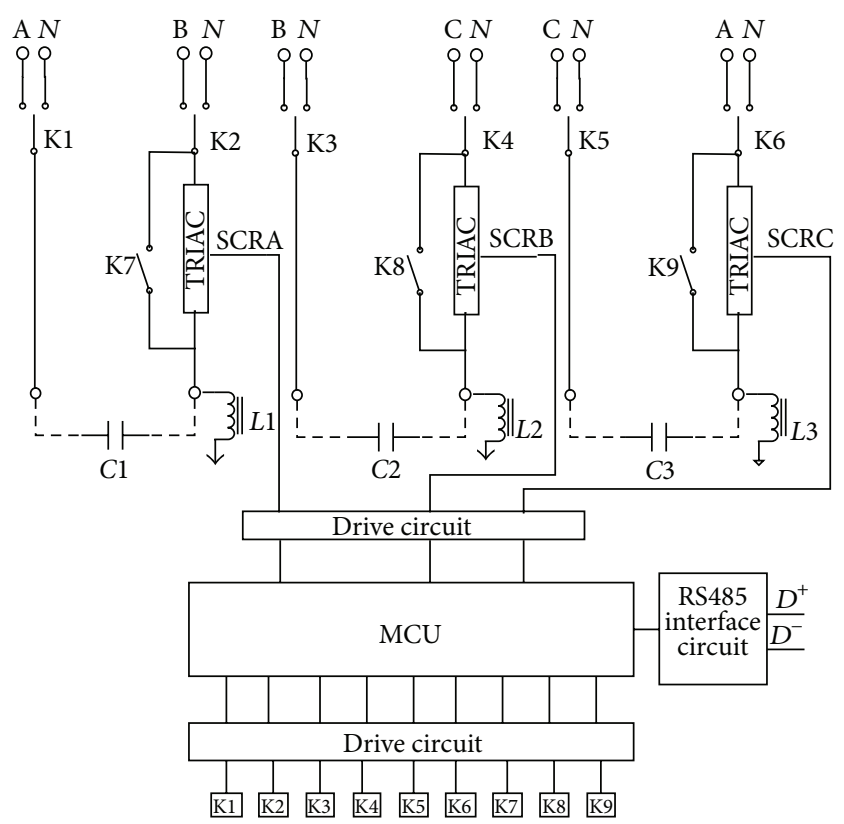

Figure 3: The structure of the intelligent grouping compound switches.

Due to the measurement difficulty and inconvenience of the load parameters, $G_{a}^{L}, G_{b}^{L}, G_{c}^{L}, B_{a}^{L}, B_{b}^{L}$, and $B_{c}^{L}$, (9) can be presented as (10) using load active power and reactive power:

$$
\begin{aligned}
& {\left[\begin{array}{c}
B_{a}^{Y} \\
B_{b}^{Y} \\
B_{c}^{Y} \\
B_{b c}^{\Delta} \\
B_{c a}^{\Delta} \\
B_{a b}^{\Delta}
\end{array}\right]} \\
& =\frac{1}{U^{2}}\left[\begin{array}{cccccc}
\frac{1}{\sqrt{3}} & -\frac{1}{\sqrt{3}} & 0 & \frac{1}{4} & \frac{1}{4} & -\frac{3}{4} \\
0 & \frac{2}{3 \sqrt{3}} & -\frac{2}{3 \sqrt{3}} & -\frac{1}{12} & -\frac{1}{12} & -\frac{1}{12} \\
-\frac{1}{\sqrt{3}} & 0 & \frac{1}{\sqrt{3}} & \frac{1}{4} & -\frac{3}{4} & \frac{1}{4} \\
-\frac{2}{3 \sqrt{3}} & 0 & \frac{2}{3 \sqrt{3}} & -\frac{1}{12} & -\frac{1}{12} & -\frac{1}{12} \\
\frac{2}{3 \sqrt{3}} & -\frac{2}{3 \sqrt{3}} & 0 & -\frac{1}{12} & -\frac{1}{12} & -\frac{1}{12}
\end{array}\right]\left[\begin{array}{c}
\frac{1}{4} \\
P_{b}^{L} \\
P_{c}^{L} \\
Q_{a}^{L} \\
Q_{b}^{L} \\
Q_{c}^{L}
\end{array}\right],
\end{aligned}
$$

where $P_{a}^{L}, P_{b}^{L}, P_{c}^{L}, Q_{a}^{L}, Q_{b}^{L}$, and $Q_{c}^{L}$ are the load active power and reactive power of each phase, respectively. 


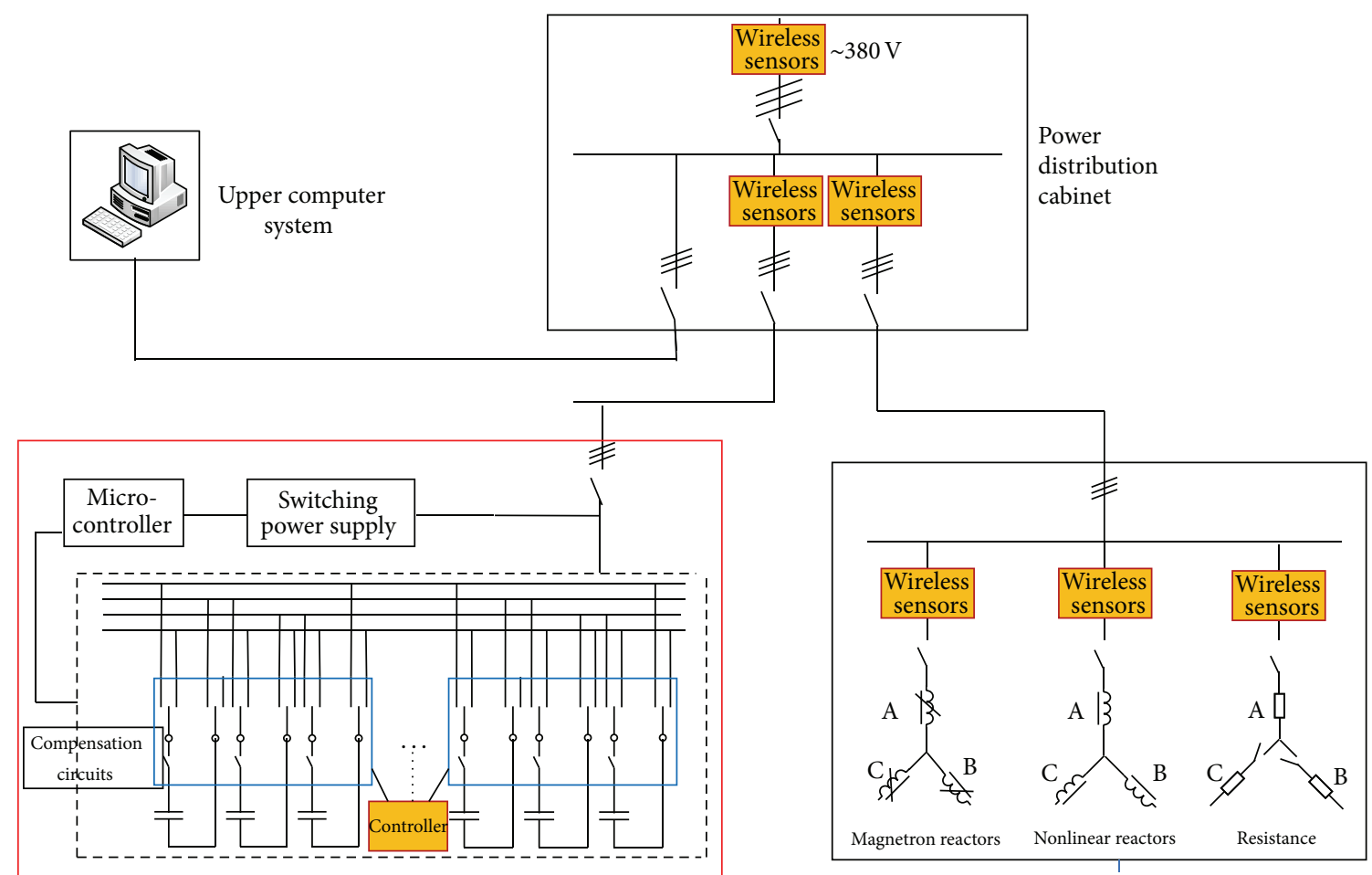

Prototype compensator

Unbalanced linear/nonlinear loads

FIGURE 4: The hardware system structure of the application platform.

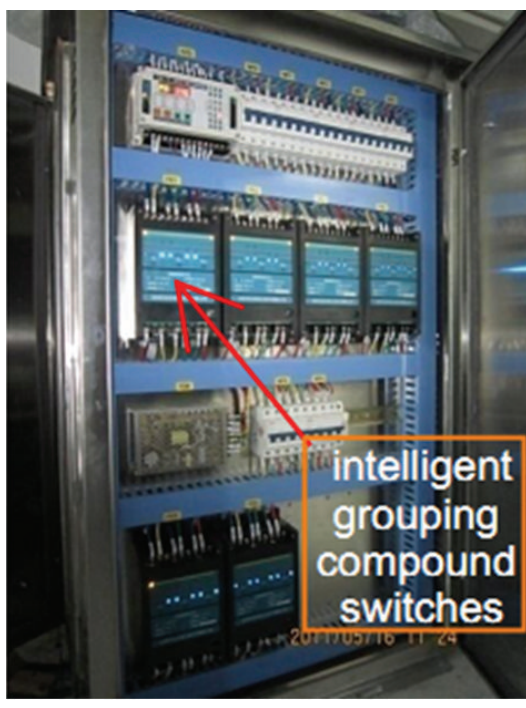

(a)

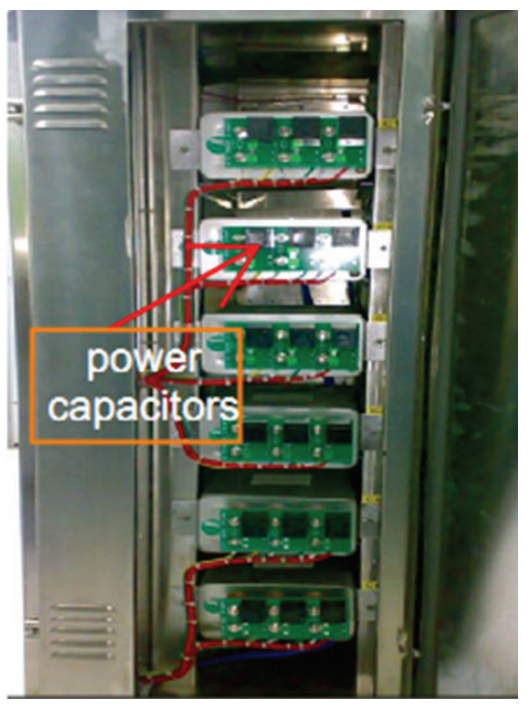

(b)

Figure 5: The photos of the prototype compensator. (a) The front of the compensator (controller and the intelligent grouping compound switches). (b) The back of the compensator (capacitor banks).

3.2. Positive Sequence Online Extraction of Source Voltages. It is to be noted that the previous method is suitable when the source voltages are balanced but neither unbalanced in magnitudes nor phase angles nor distorted. When the source voltages are unbalanced and distorted, they can no longer be directly fed to the shunt compensation algorithm (10). Therefore, to improve the performance of the algorithm, the on-line extraction of positive sequence of source voltages at the point of common coupling is done using the powerinvariant instantaneous symmetrical component transformation $[13,22]$. This is given by

$$
\left[\begin{array}{l}
v_{s a 0} \\
v_{s a+} \\
v_{s a-}
\end{array}\right]=\frac{1}{\sqrt{3}}\left[\begin{array}{ccc}
1 & 1 & 1 \\
1 & a & a^{2} \\
1 & a^{2} & a
\end{array}\right]\left[\begin{array}{l}
v_{s a} \\
v_{s b} \\
v_{s c}
\end{array}\right] .
$$




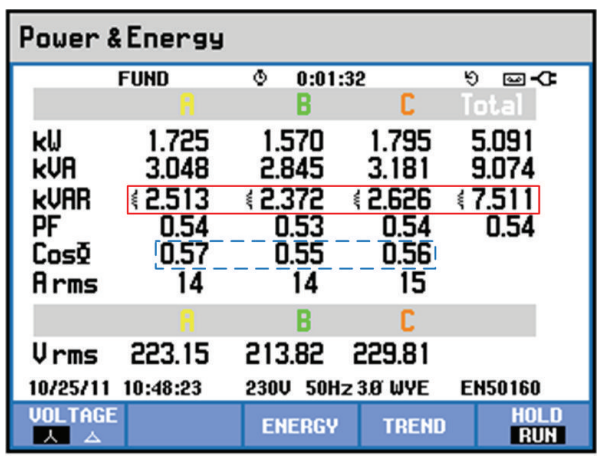

(a)

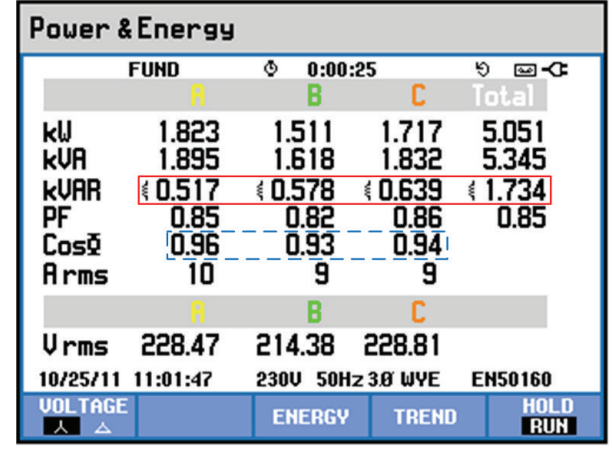

(b)
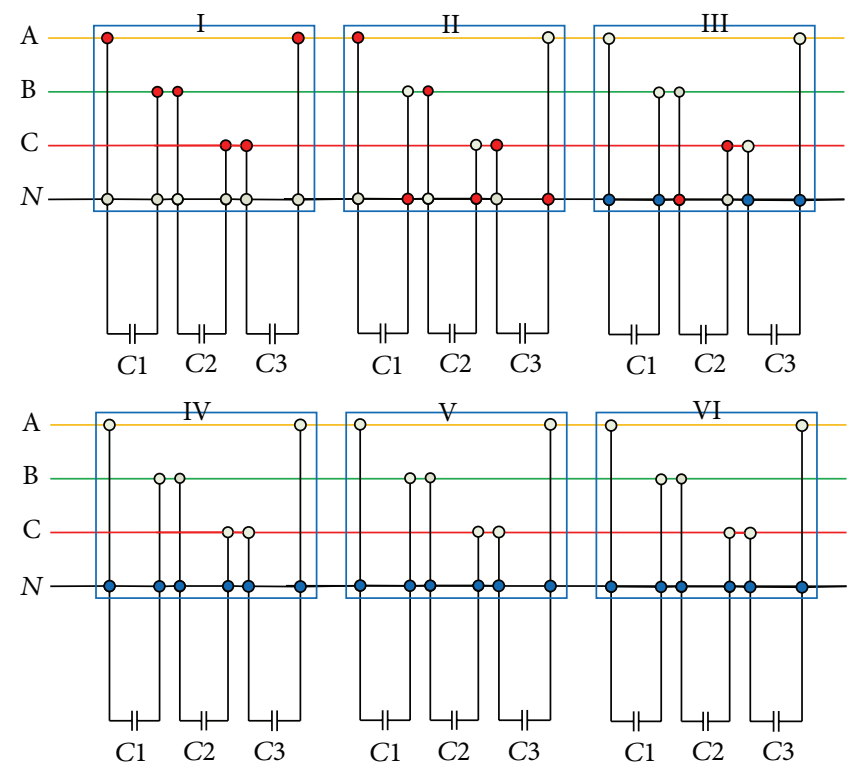

(c)

Figure 6: Test results with balanced linear inductive load. (a) The power factor and reactive power before compensation. (b) The power factor and reactive power after compensation. (c) The state of the intelligent grouping compound switches.

The phasor symmetrical components are defined as $V_{s a 0}$, $V_{s a+}$, and $V_{s a-}$, respectively. The following equation is used to obtain the positive sequence voltage $[13,22]$ :

$$
V_{s a+}=\frac{\sqrt{2}}{T} \int_{t_{0}}^{t_{0}+T} v_{s a+} e^{-j\left(\omega t-90^{\circ}\right)} d t,
$$

where $t_{0}$ is any instant and $T$ is the duration of one cycle of supply voltage. After this extraction, the shunt compensation algorithm (10) is now fed only positive sequence voltage of the unbalanced and distorted source voltages.

\subsection{Application of Intelligent Grouping Compound Switches.} Intelligent grouping compound switches are the important parts of the proposed compensator, whose structure is shown in Figure 3.

The intelligent grouping compound switches is mainly composed of magnetic latching relay $\mathrm{K} 1, \mathrm{~K} 2, \mathrm{~K} 3, \mathrm{~K} 4, \mathrm{~K} 5, \mathrm{~K} 6$, $\mathrm{K} 7, \mathrm{~K} 8$, and $\mathrm{K} 9$ and bidirectional triode thyristor TRIAC.
The magnetic latching relay and TRIAC are controlled by MCU controlled by microcontroller. When switching the capacitors, magnetic latching relay $\mathrm{K} 1, \mathrm{~K} 2, \mathrm{~K} 3, \mathrm{~K} 4$, $\mathrm{K} 5$, and $\mathrm{K} 6$ complete the grouping according to the received command, so that each single-phase capacitor can be connected between phases or between phase and ground, and then the TRIAC is triggered at the time of voltage zero crossing, making the capacitors connected to the circuit. After a few tens of milliseconds of delay, K7, K8, and $\mathrm{K} 9$ are conducted, and the capacitors currents begin to flow though the relay. Then, remove the trigger signal and the capacitors switching action is completed.

3.4. Application of Wireless Voltage/Current Sensors. With the developing of the computer and communications technology, the application of wireless sensors is increasing, especially in the smart grid. In order to facilitate monitoring of the system and reduce the use of the communication cables, wireless sensors are adopted in this paper. The wireless sensors are 


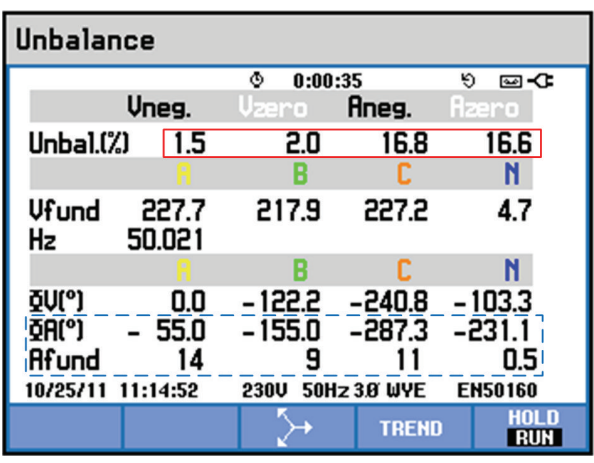

(a)

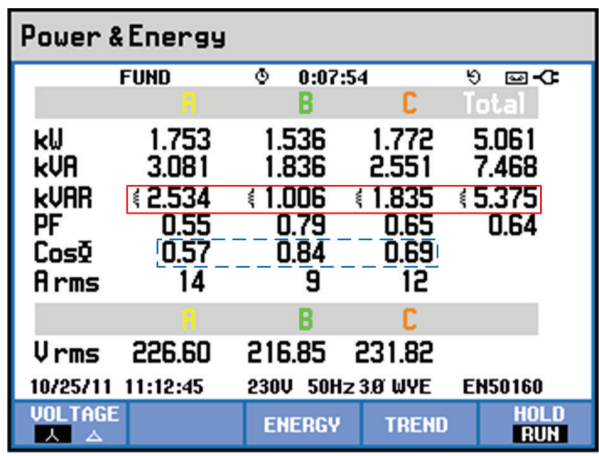

(c)

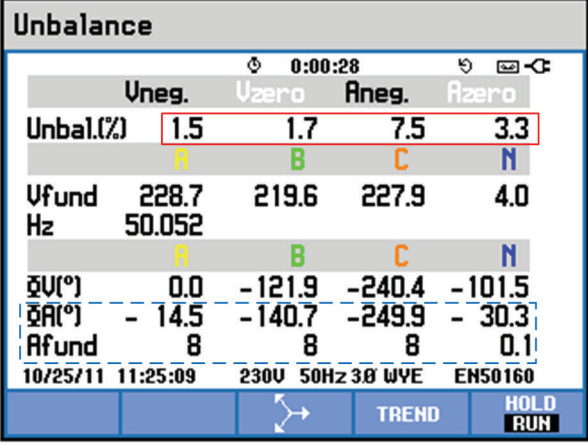

(b)

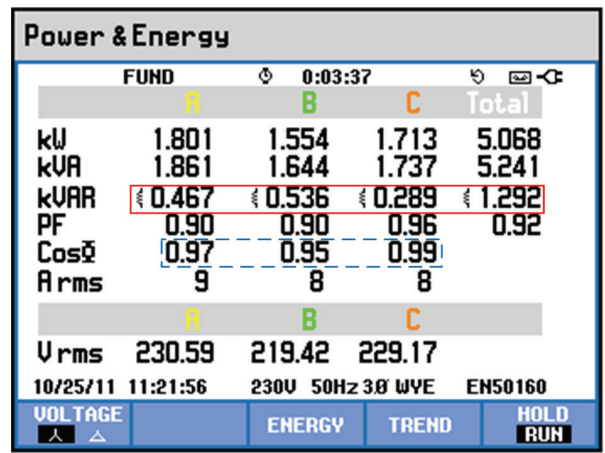

(d)
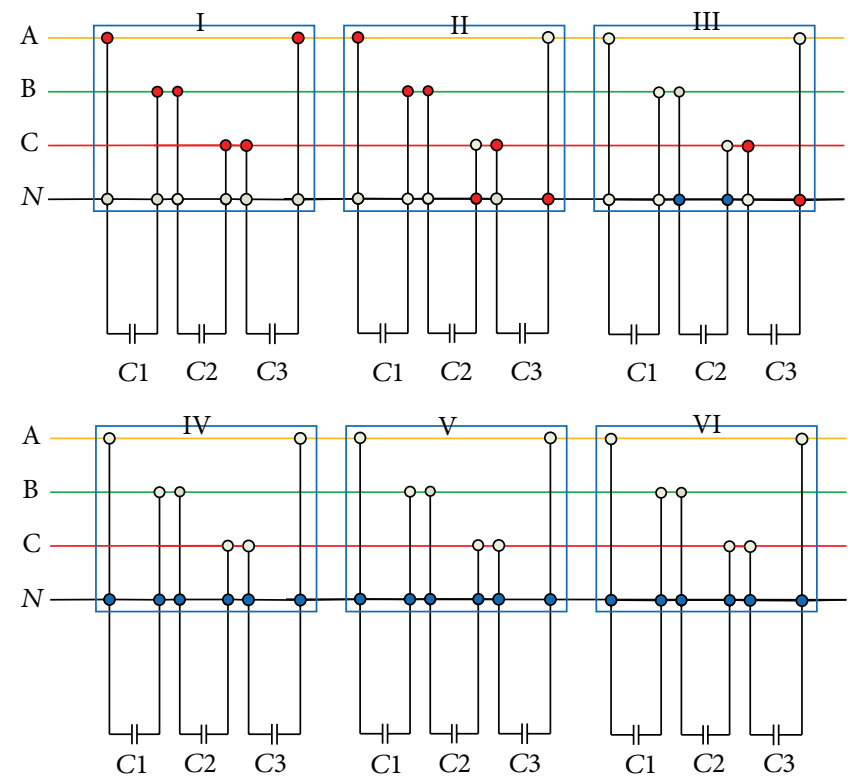

(e)

Figure 7: Test results with unbalanced linear inductive load. (a) The unbalanced load currents and neutral current and the unbalance of voltage and current. (b) The balanced source currents and neutral current and the unbalance of voltage and current. (c) The active power, reactive power, and power factors on the load side. (d) The active power, reactive power, and power factors on the load side on the source side. (e) The state of the intelligent grouping compound switches.

used to provide the load parameters for the controller of the compensator and the upper computer system. The wireless sensors are installed in each phase of the loads, as well as the compensator and the power distribution cabinet. The schematic diagram is shown in Figure 4.

\section{Application Results and Analysis}

To verify and test the application effect of the compensator, a prototype compensator is developed and applied to Shenbei New District of Shenyang. The hardware system structure 


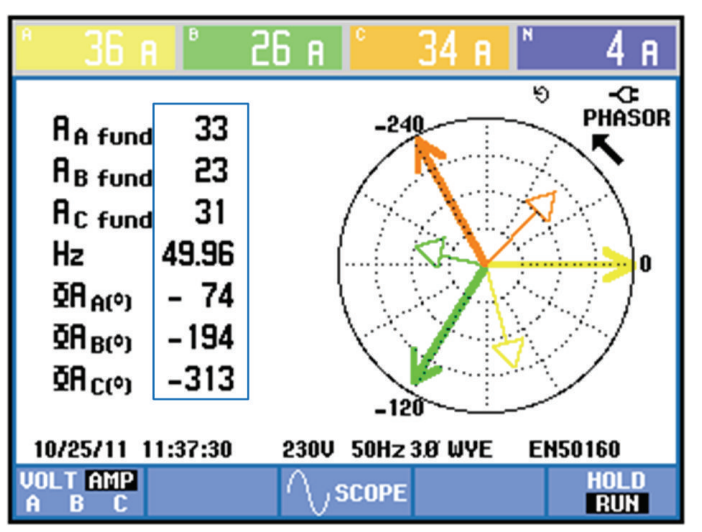

(a)

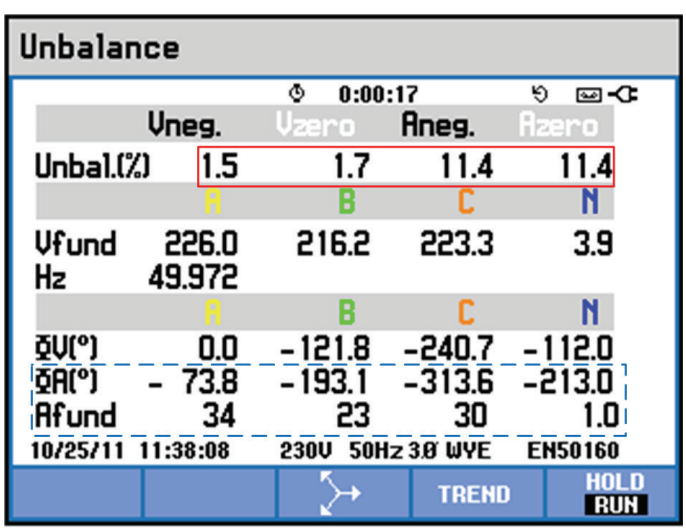

(c)

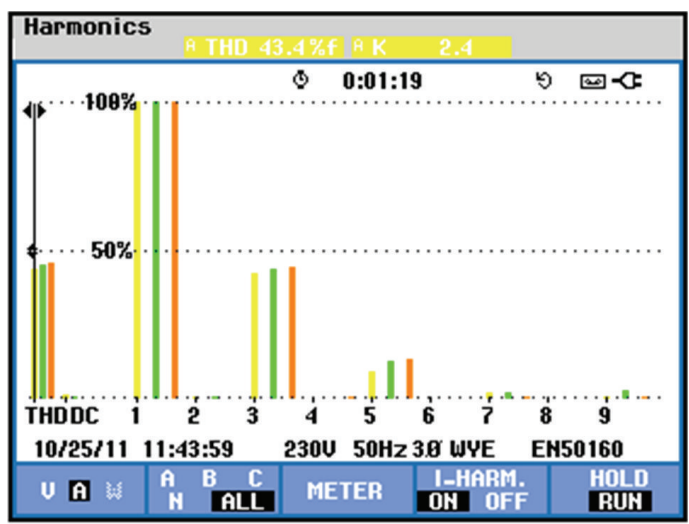

(e)

\begin{tabular}{|c|c|c|c|c|}
\hline \multicolumn{5}{|c|}{ Power \& Energy } \\
\hline \multicolumn{2}{|r|}{ FUND } & $\begin{array}{ll}0: 00: 3 \\
B\end{array}$ & C & $y \quad$ 回 6 \\
\hline $\begin{array}{l}\text { kUJ } \\
\text { kUR } \\
\text { kURR } \\
\text { PF } \\
\text { Cos } \\
\text { Rrms }\end{array}$ & \begin{tabular}{|c|}
2.259 \\
7.815 \\
7.481 \\
0.26 \\
0.29 \\
38 \\
38
\end{tabular} & $\begin{array}{r}1.547 \\
4.608 \\
\xi 4.341 \\
--\frac{0.30}{0.34}- \\
--\frac{24}{24}-\end{array}$ & $\begin{array}{r}1.870 \\
6.630 \\
6.361 \\
-\frac{0.25}{0.28} \\
-\frac{33}{33}\end{array}$ & $\begin{array}{r}5.676 \\
19.05 \\
18.18 \\
0.27\end{array}$ \\
\hline $\begin{array}{l}\text { Urms } \\
10 / 25 / 11\end{array}$ & $\begin{array}{c}226.95 \\
\text { 11:31:41 }\end{array}$ & $\begin{array}{l}\text { B } \\
214.91 \\
230050 \mathrm{~Hz}\end{array}$ & $\begin{array}{c}\text { C } \\
223.45 \\
38 \text { WYE }\end{array}$ & EN50160 \\
\hline $\begin{array}{l}\text { UOLTAGE } \\
\text { ᄉ } \triangle\end{array}$ & & EHERGY & TREFD & $\begin{array}{l}\text { HOLD } \\
\text { RUH }\end{array}$ \\
\hline
\end{tabular}

(g)

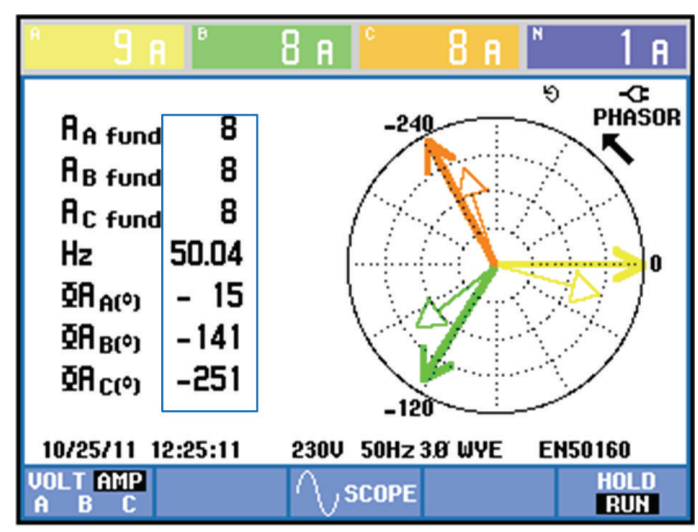

(b)

\begin{tabular}{|c|c|c|}
\hline \multicolumn{3}{|l|}{ Unbalance } \\
\hline & $0: 00: 12$ & $y$ 国政 \\
\hline Uneg. & Uzero Pneg. & fizero \\
\hline \multirow{2}{*}{ Unbal.(\%) $\quad 1.2$} & 6.4 & 1.9 \\
\hline & C & N \\
\hline $\begin{array}{ll}\text { Ufund } & 229.9 \\
\mathrm{~Hz} & 50.049\end{array}$ & 223.6 & 2.1 \\
\hline \multirow[t]{2}{*}{ 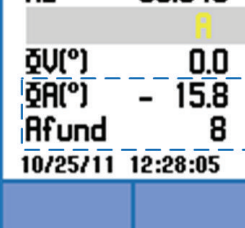 } & 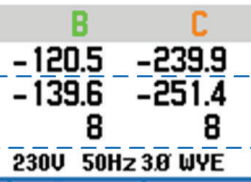 & $\begin{array}{r}N \\
-142.9 \\
-\quad 6.6 \\
0.0 \\
-E \overline{5} 50160\end{array}$ \\
\hline & TREND & $\begin{array}{l}\text { HOLD } \\
\text { RUUH }\end{array}$ \\
\hline
\end{tabular}

(d)

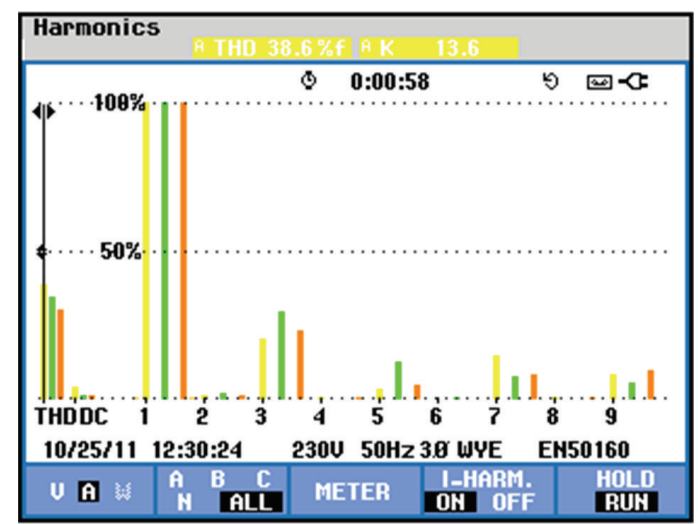

(f)

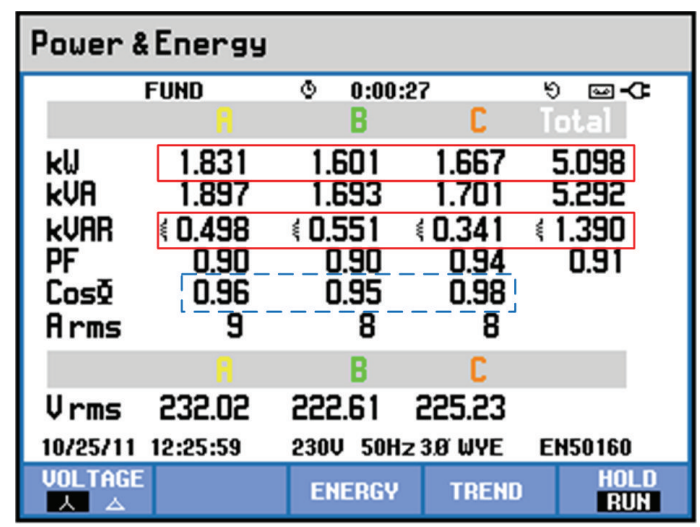

(h)

FIGURE 8: Continued. 

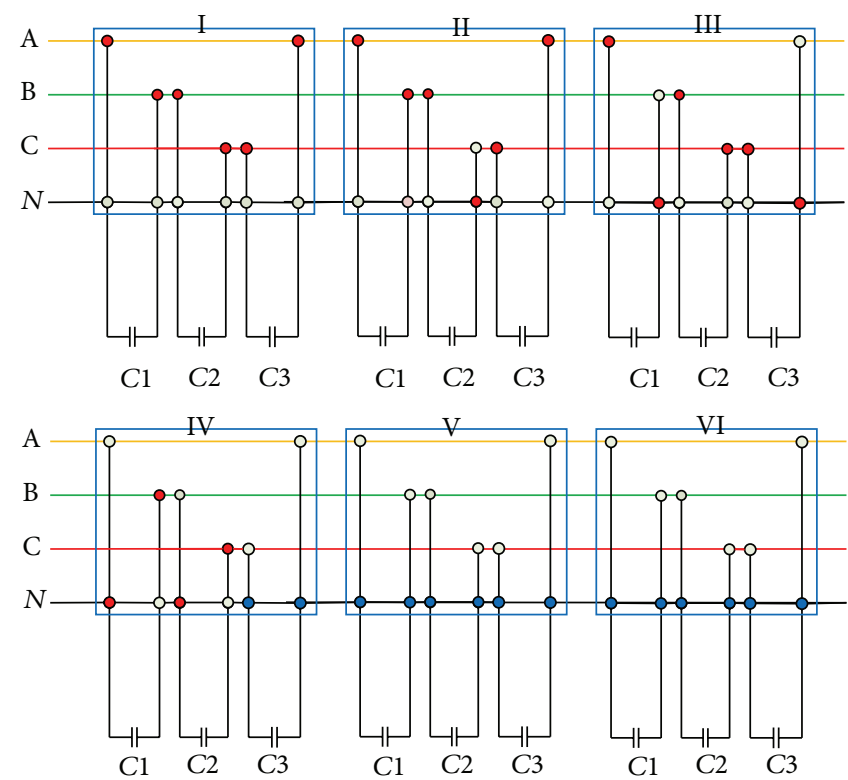

(i)

Figure 8: Test results with unbalanced nonlinear inductive load. (a) The unbalanced load currents. (b) The balanced source currents. (c) The unbalance of voltage and current before compensation. (d) The unbalance of voltage and current after compensation. (e) TDH of load current. (f) TDH of source current. (g) The active power, reactive power, and power factors on the load side. (h) The active power, reactive power, and power factors on the source side. (i) The state of the intelligent grouping compound switches.

of the test platform is shown in Figure 4, which includes a host computer, a power distribution cabinet, unbalanced linear/nonlinear loads, and the prototype compensator. The host computer is used to monitor the system running status, whose program is written in VB.NET. The host computer is connected to the power distribution cabinet. The needed parameters of the controller and the host computer are applied through the wireless sensors, and the parameters are mainly voltages and currents. The load cabinet is composed of 20 kvar single-phase adjustable reactor, 10 kvar nonlinear reactor, and $5 \mathrm{kw}$ single-phase resistance. The capacitance of the prototype compensator is $36 \mathrm{kvar}$.

The photo of the prototype compensator is shown in Figure 5, in which the intelligent grouping compound switches are controlled by the controller made with ARM chip LPC2138. The program is written in $\mathrm{C} / \mathrm{C}++$ for the compensation algorithm.

For the application tests, the prototype compensator is tested for three different load conditions: (1) performance of the prototype compensator under balanced linear inductive load; (2) performance of the prototype compensator under unbalanced linear inductive load; (3) performance of the prototype compensator under unbalanced nonlinear inductive load. The details are discussed in the following section.

4.1. Performance of the Prototype Compensator under Balanced Linear Inductive Load. The power factor and reactive power on source side before compensation and after compensation is shown in Figures 6(a) and 6(b), respectively, and it is demonstrated that the reactive power of the load is compensated by the prototype compensator. The power factor is improved from 0.57 to 0.96 . The state of the intelligent grouping compound switches is shown in Figure 6(c).

4.2. Performance of the Prototype Compensator under Unbalanced Linear Inductive Load. The unbalanced load currents, neutral current and balanced source currents, neutral current, along with PCC voltage are shown in Figures 7(a) and 7(b), respectively. And the unbalance of voltage and current before and after compensation is also shown in Figures 7(a) and 7(b), respectively. The source currents are equal and balanced while the load currents are unbalanced. And the unbalance of currents and voltage is improved greatly. The active power, reactive power, and power factors on the load side and source side are shown in Figures 7(c) and 7(d), respectively. It is observed that on the source side the power factor is improved from 0.69 to 0.99 (phase C), the active power is balanced, and the reactive power is very small. The state of the intelligent grouping compound switches is shown in Figure 7(e). These test results demonstrate the load balancing and reactive power compensation by the proposed compensator with the linear load.

4.3. Performance of the Prototype Compensator under Unbalanced Nonlinear Inductive Load. The prototype compensator is tested for harmonic elimination, load balancing, and reactive power compensation by connecting an unbalanced nonlinear inductive load. The unbalanced load currents and balanced source currents are shown in Figures 8(a) and 8(b), respectively, and the unbalance at the load side and the source 
side is shown in Figures 8(c) and 8(d), respectively. It is demonstrated that improvement of the unbalance is achieved by the compensator. The THD and harmonic spectra of load current and source current are shown in Figures 8(e) and $8(\mathrm{f})$, respectively, showing that the THD is $34.5 \%$ at the load side and $4.6 \%$ at the source side. The active power, reactive power, and power factors at the load side and the source side are shown in Figures $8(\mathrm{~g})$ and $8(\mathrm{~h})$, respectively. It is observed that at the source side the power factor is improved greatly, the active power is balanced, and the reactive power is compensated greatly by the compensator. The state of the intelligent grouping compound switches is shown in Figure 8(i). These test results demonstrate the load balancing, harmonic elimination, and reactive power compensation by the proposed compensator with the unbalanced nonlinear inductive load.

\section{Conclusion}

The present paper sustains a new method applied for load balancing and reactive power compensation by using the model containing only capacitor banks which are controlled with intelligent grouping compound switches. This method can be applied for the low voltage three-phase four-wire distribution networks. The analysis and implementation of the new method and the prototype compensator developed have been carried out and applied to Shenbei New District of Shenyang. The good performance has been demonstrated for load balancing, reactive power compensation, neutral current elimination, and harmonic elimination in the experiment.

The compensator dimensioned using the presented model contains only capacitor banks, giving to the solution some clear advantages:

(i) smaller volume and lower costs by using only capacitor banks and intelligent grouping compound switches;

(ii) evenif it contains only capacitors, the compensators allow the total reactive power compensation on the ensemble of the three phases and the perfect balancing of the load or mitigation enough of the dissymmetry;

(iii) the units component of the capacitor banks can be small enough to allow an on-line control good enough by intelligent grouping compound switches, which also reduce the costs;

(iv) the structure of the compensator can be easily modified to increase or decrease the reactive capacitive power installed.

So, this simple and efficient way of load balancing and reactive power compensation can be adopted which can be applied for online control.

\section{Acknowledgments}

This work was supported by the National Natural Science Foundation of China (60904101, 61203026, and 61104099), the Fundamental Research Funds for the Central Universities (N110404031, N110304004, and N100104102), and China Postdoctoral Science Foundation (20090461187).

\section{References}

[1] R. C. Dugan, M. F. Mcgranaghan, and H. W. Beaty, Electric Power Systems Quality, McGraw Hill, New York, NY, USA, 2nd edition, 2006.

[2] M. M. Antonio, Power Quality: Mitigation Technologies in a Distributed Environment, Springer, London, UK, 2007.

[3] F. F. Ewald and A. S. M. Mohammad, Power Quality in Power Systems and Electrical Machines, Elsevier Academic Press, London, UK, 2008.

[4] H. Jouini, K. Jemai, and S. Chebbi, "Voltage stability control of electrical network using intelligent load shedding strategy based on fuzzy logic," Mathematical Problems in Engineering, vol. 2010, Article ID 341257, 17 pages, 2010.

[5] S.-Y. Lee and C.-J. Wu, "Reactive power compensation and load balancing for unbalanced three-phase four-wire system by a combined system of an SVC and a series active filter," IEE Proceedings Electric Power Applications, vol. 147, no. 6, pp. 563578, 2000.

[6] S. Y. Lee and C. J. Wu, "On-line reactive power compensation schemes for unbalanced three phase four wire distribution feeders," IEEE Transactions on Power Delivery, vol. 8, no. 4, pp. 1958-1965, 1993.

[7] U. K. Rao, M. K. Mishra, and A. Ghosh, "Control strategies for load compensation using instantaneous symmetrical component theory under different supply voltages," IEEE Transactions on Power Delivery, vol. 23, no. 4, pp. 2310-2317, 2008.

[8] J. Dixon, Y. del Valle, M. Orchard, M. Ortúzar, L. Morán, and C. Maffrand, "A full compensating system for general loads, based on a combination of thyristor binary compensator, and a PWM-IGBT active power filter," IEEE Transactions on Industrial Electronics, vol. 50, no. 5, pp. 982-989, 2003.

[9] B. R. Lin and C. H. Huang, "Implementation of a threephase capacitor-clamped active power filter under unbalanced condition," IEEE Transactions on Industrial Electronics, vol. 53, no. 5, pp. 1621-1630, 2006.

[10] G. Escobar, A. M. Stanković, and P. Mattavelli, "An adaptive controller in stationary reference frame for D-Statcom in unbalanced operation," IEEE Transactions on Industrial Electronics, vol. 51, no. 2, pp. 401-409, 2004.

[11] B. Blažič and I. Papič, "Improved D-Statcom control for operation with unbalanced currents and voltages," IEEE Transactions on Power Delivery, vol. 21, no. 1, pp. 225-233, 2006.

[12] B. Singh and J. Solanki, "Load compensation for diesel generator-based isolated generation system employing DSTATCOM," IEEE Transactions on Industry Applications, vol. 47, no. 1, pp. 238-244, 2011.

[13] M. K. Mishra, A. Ghosh, A. Joshi, and H. M. Suryawanshi, "A novel method of load compensation under unbalanced and distorted voltages," IEEE Transactions on Power Delivery, vol. 22, no. 1, pp. 288-295, 2007.

[14] M. K. Mishra and K. Karthikeyan, "An investigation on design and switching dynamics of a voltage source inverter to compensate unbalanced and nonlinear loads," IEEE Transactions on Industrial Electronics, vol. 56, no. 8, pp. 2802-2810, 2009.

[15] A. E. Leon, J. M. Mauricio, J. A. Solsona, and A. GomezExposito, "Adaptive control strategy for VSC-based systems 
under unbalanced network conditions," IEEE Transactions on Smart Grid, vol. 1, no. 3, pp. 311-319, 2010.

[16] C. S. Chen, C. T. Tsai, C. H. Lin, W. L. Hsieh, and T. T. $\mathrm{Ku}$, "Loading balance of distribution feeders with loop power controllers considering photovoltaic generation," IEEE Transactions on Power Systems, vol. 26, no. 3, pp. 1762-1768, 2011.

[17] H. Zhang, D. Yang, and T. Chai, "Guaranteed cost networked control for T-S fuzzy systems with time delays," IEEE Transactions on Systems, Man, and Cybernetics, Part C, vol. 37, no. 2, pp. 160-172, 2007.

[18] H. Zhang, Z. Wang, and D. Liu, "Global asymptotic stability of recurrent neural networks with multiple time-varying delays," IEEE Transactions on Neural Networks, vol. 19, no. 5, pp. 855$873,2008$.

[19] A. Prasai, J. Sastry, and D. M. Divan, "Dynamic capacitor (D-CAP): an integrated approach to reactive and harmonic compensation," IEEE Transactions on Industry Applications, vol. 46, no. 6, pp. 2518-2525, 2010.

[20] P. Jintakosonwit, S. Srianthumrong, and P. Jintagosonwit, "Implementation and performance of an anti-resonance hybrid delta-connected capacitor bank for power factor correction," IEEE Transactions on Power Electronics, vol. 22, no. 6, pp. 25432551, 2007.

[21] A. Panǎ, A. Bǎloi, and F. Molnar-Matei, "Load balancing by unbalanced capacitive shunt compensation-a numerical approach," in Proceedings of the 14th International Conference on Harmonics and Quality of Power (ICHQP '10), pp. 1-6, September 2010.

[22] A. Ghosh and G. Ledwich, Power Quality Enhancement Using Custom Power Devices, Kluwer Academic, London, UK, 2002. 


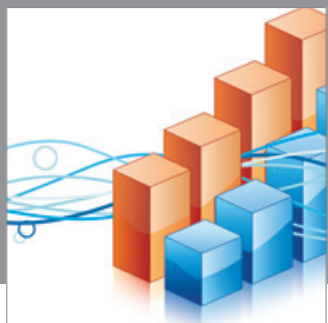

Advances in

Operations Research

mansans

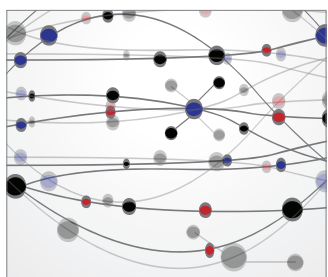

The Scientific World Journal
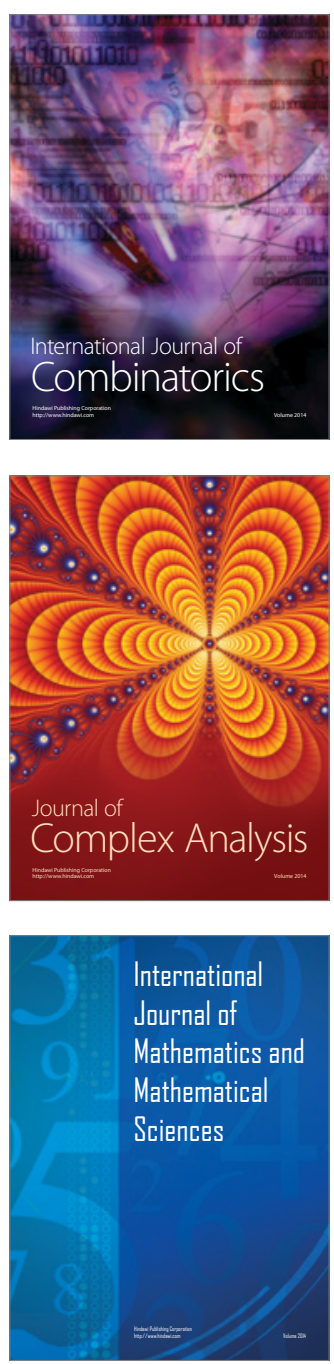
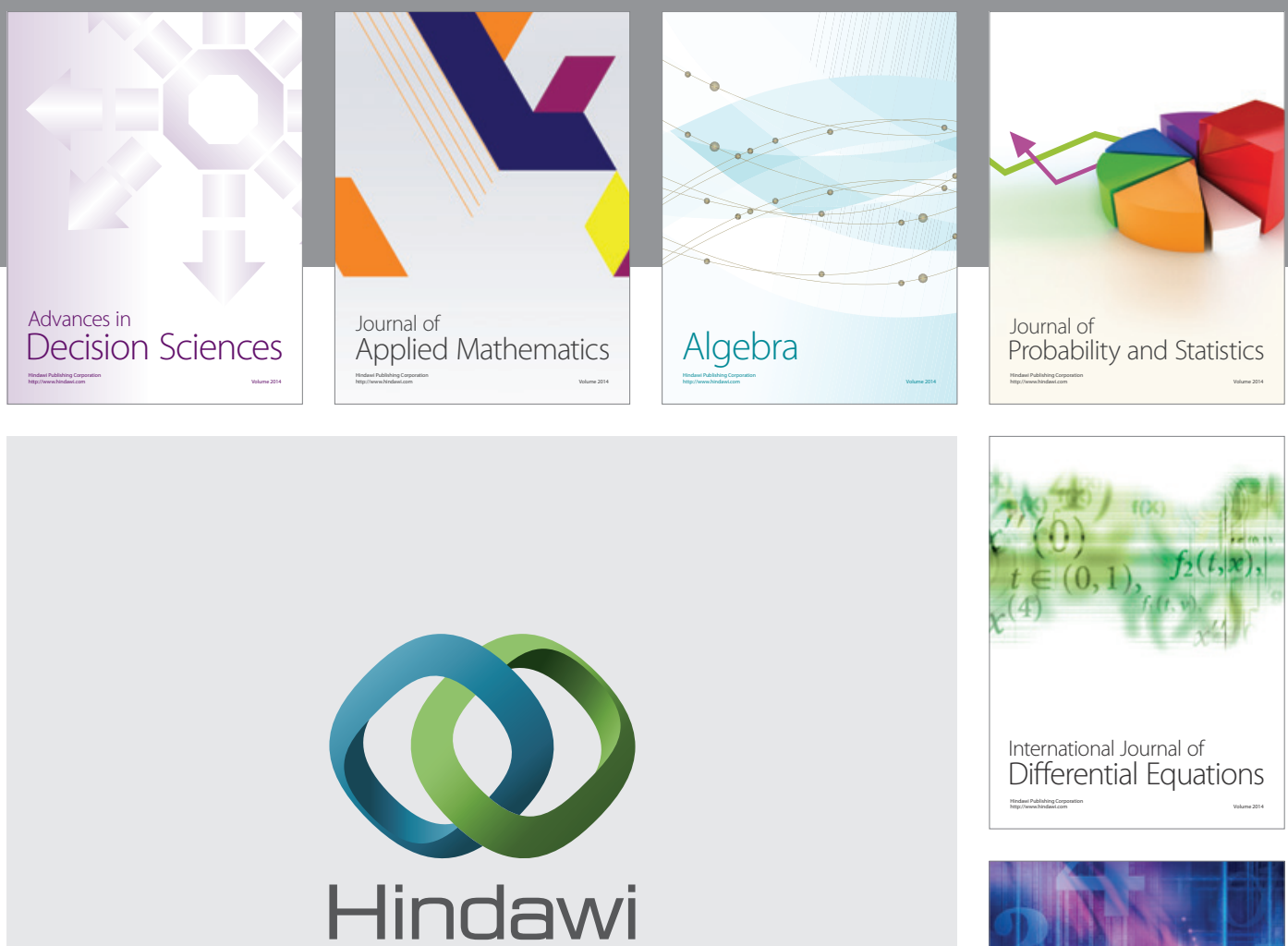

Submit your manuscripts at http://www.hindawi.com
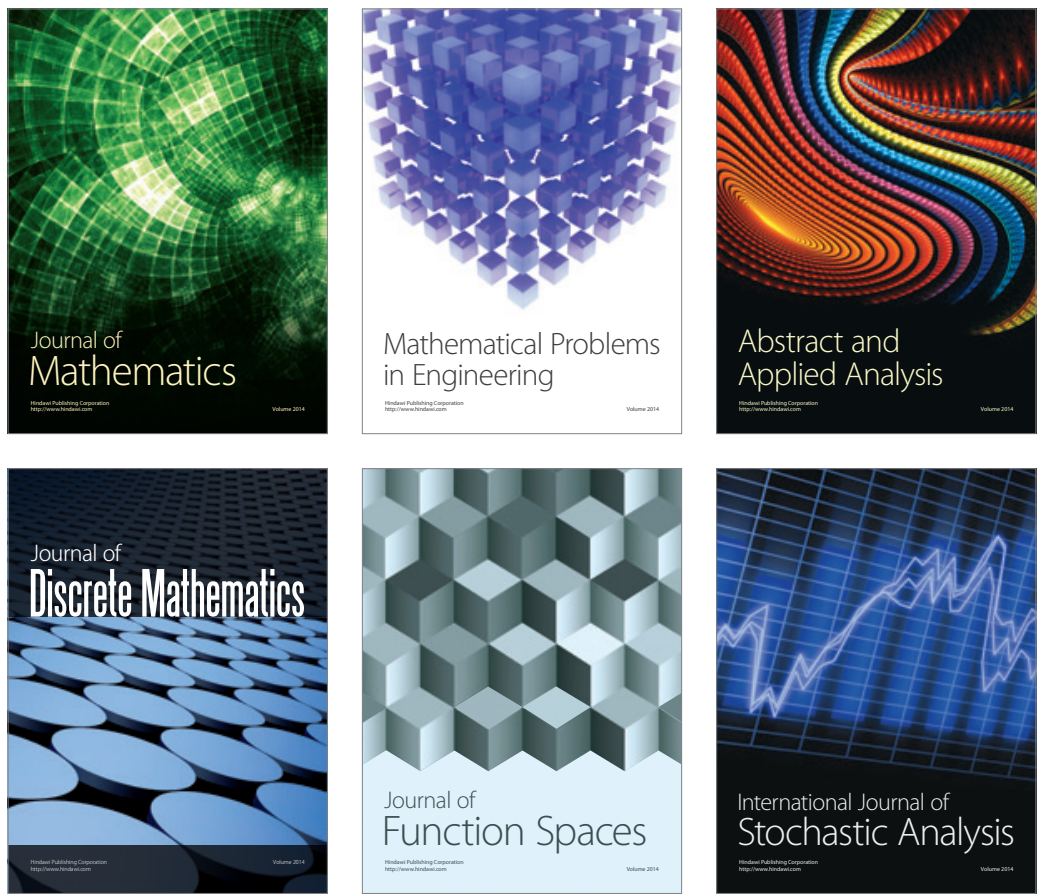

Journal of

Function Spaces

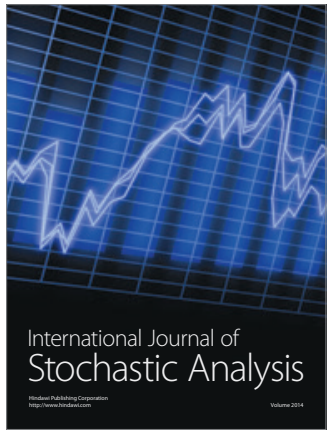

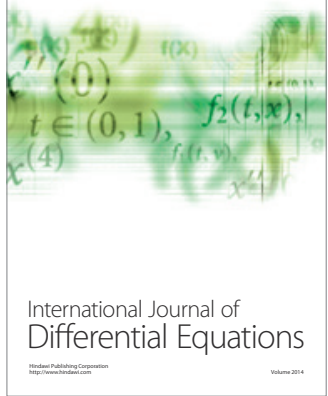
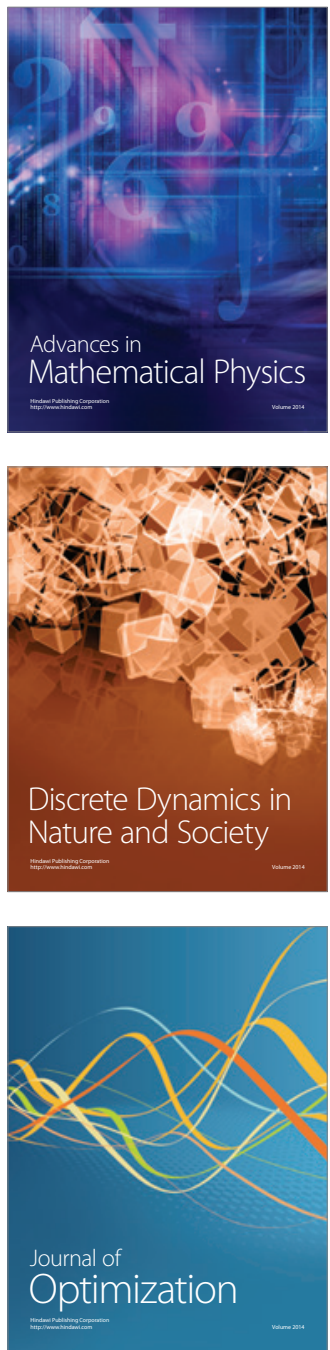